\title{
Epidemiological Studies on UV-Related Cataract in Climatically Different Countries
}

\author{
Kazuyuki Sasaki ', Hiroshi Sasaki ${ }^{1}$, Masami Kojima ${ }^{1}$, Ying Bo Shui ${ }^{1,3}$, Otto Hockwin ${ }^{1}$, \\ Fridbert Jonasson ${ }^{2}$, Hong Ming Cheng ${ }^{3,4}$, Masaji Ono ${ }^{5}$, and Nobuyo Katoh ${ }^{6}$
}

\begin{abstract}
Cataract epidemiological surveys applying objective judgement through lens images in the climatically different places of Noto and Amami, Japan, Singapore and Reykjavik, Iceland yielded several significant results about the influence of solar UV. 1) The percentage of transparent and of lens opacification was significantly higher in the Reykjavik subjects than in the Singaporeans. 2) The percentages including early changes were higher in Amami and Singapore than in Noto and Reykjavik. 3) Progressed lens opacification was highest in Singapore. While the main type of lens opacification was cortical in Noto and Reykjavik, that of Singapore was nuclear. 4 ) A significant correlation between cortical opacification and the history of time spent outdoors was noticed. The UV risk for formation and/or progression of cortical opacification should be acceptable from the epidemiological standpoint.
\end{abstract}

J Epidemiol, 1999 ; 9 : S33-S38.

cataract prevalence, UV scenario, races, image analysis of the lens, risk factors, time spent outdoors

Age-related cataract is recognized world wide as a top ranked eye disease that induces the deterioration of vision 1 ). Since at present there is no effective medication to prevent cataract appearance or progression, the search for risk factors of cataract formation with the aim of prevention is meaningful. Among several risks for cataract formation in human eyes ${ }^{2}$, solar UV-exposure to the eye in particular has been considered as a possible important risk. In order to confirm UV action to the lens, both experimental and epidemiological studies are required. UV-induced cataract in animal eyes is an established cataract model in experimental lens research. However, only a limited number of studies have proved it from an epidemiological standpoint $3,4,5,6.7,8,9)$. Although some positive conclusions which may link UV rays as a risk for cataract have been made, additional studies are still necessary to completely prove the UV scenario. Most of the previous epidemiological studies were performed in one area with limited subjects and no studies which aimed to confirm UV exposure as a risk for cataract formation have been performed by the same study group with the same methodology. Consequently, no exactly comparable studies with the above aim have been made until recently. During the last few years, the authors' group has fortunately had the occasion to perform cataract epidemiological surveys in several climatically different places in the world. The survey places are the main and southern islands of Japan, Iceland and Singapore. Although the studies introduced in this article are on going, a few of the survey's results are briefly described.

\section{SUBJECTS AND METHODS}

The subjects of the cataract epidemiological surveys per-

\footnotetext{
${ }^{1}$ Department of Ophthalmology, Kanazawa Medical University, Uchinada, Japan.

${ }^{2}$ Department of Ophthalmology, Iceland University, Reykjavik, Iceland.

${ }^{3}$ Singapore Eye Research Institute, Singapore.

${ }^{4}$ Schepence Eye Association, Boston, USA.

${ }^{5}$ National Institute of Environmental Research,Tsukuba, Japan.

${ }^{6}$ Department of Public Health, Juntenndo University, School of Medicine, Tokyo, Japan.

Address for correspondence : Kazuyuki Sasaki, M.D. Department of Ophthalmology, Kanazawa Medical University, Daigakumachi, 1-1. Uchinada, 920-0293 Japan.
} 
formed in Noto and Amami Japan ${ }^{10)}$, Reykjavik (Iceland) and Singapore are individuals over age 50 who were living in the survey area. At present, the numbers of the lens findings for analysis are 884, 301, 993 and 468, respectively (Table 1). The data collection applied in the surveys were based on randomized populations in the Reykjavik survey. The participants in the other three surveys were found through announcements by the local government and/or local newspapers and TV. The subjects in Singapore were limited to Chinese Singaporeans who had lived in the city of Singapore for a long time. The two Japanese subject groups consisted of participants who lived in the limited area of the survey places and responded to governmental calls. According to the Helcinki declaration, the aim of study was cleary explained to the participants. According to meteorological data, the average temperature is $5{ }^{\circ} \mathrm{C}$ in Reykjavik, $27.1^{\circ} \mathrm{C}$ in Singapore, $15.0^{\circ} \mathrm{C}$ in Noto and $21.3^{\circ} \mathrm{C}$ in Amami. The relative UV exposure to the earth in Iceland is 50 units $/ \mathrm{m}^{2}$ Noto is 180 units $/ \mathrm{m}^{2}$, Amami is 250 units $/ \mathrm{m}^{2}$ and Singapore is 380 units $/ \mathrm{m}^{2}$.

The same methodology was applied in all the survey places. The ophthalmological examinations performed were measurement of visual acuity, tonometry, slit lamp examination of the anterior eye segment with and without pupil dilation and fundus examination. Non-contact specular microscopy of the corneal endothelium was also examined in the Singapore survey. Scheimpflug slit photographs of the anterior eye segment were taken under non dilated and maximum dilated pupil utilizing an anterior eye segment analysis system (Nidek EAS $1000)^{11,12}$. Findings of the optic disc and macular area were taken by a stereo-scopic fundus camera (Nidek 3 - Dx / NM) under dilated pupil.

The grading of cortical and subcapsular opacification followed the Japanese Cooperative Cataract Epidemiological Study Group System (JCCESG system) ${ }^{13}{ }^{13}$. The grading of the nuclear opacification followed the Kanazawa Medical University System (KMU system) which is a modified version of the JCCESG system ${ }^{14)}$. Although the KMU system classifies a 4 step grading, to avoid confusion, grades III and IV were finally unified as grade III ( Figure 1).

The assessment of lens opacification was done using Scheimpflug and retroillumination images. A few cases with non-analyzable images were judged by experienced examiners with the help of standard photos of the system. Grading of cataract through slit lamp was judged by fixed investigators

Table 1. Subjects for the analysis of lens changes.

\begin{tabular}{ccccc}
\hline Subject groups & Race & Male & Female & Total \\
\hline Reykjavik & Caucasian & 444 & 549 & 993 \\
Singapore & Chinese & 206 & 262 & 468 \\
Noto & Japanese & 265 & 619 & 884 \\
Amami & Japanese & 94 & 207 & 301 \\
\hline
\end{tabular}

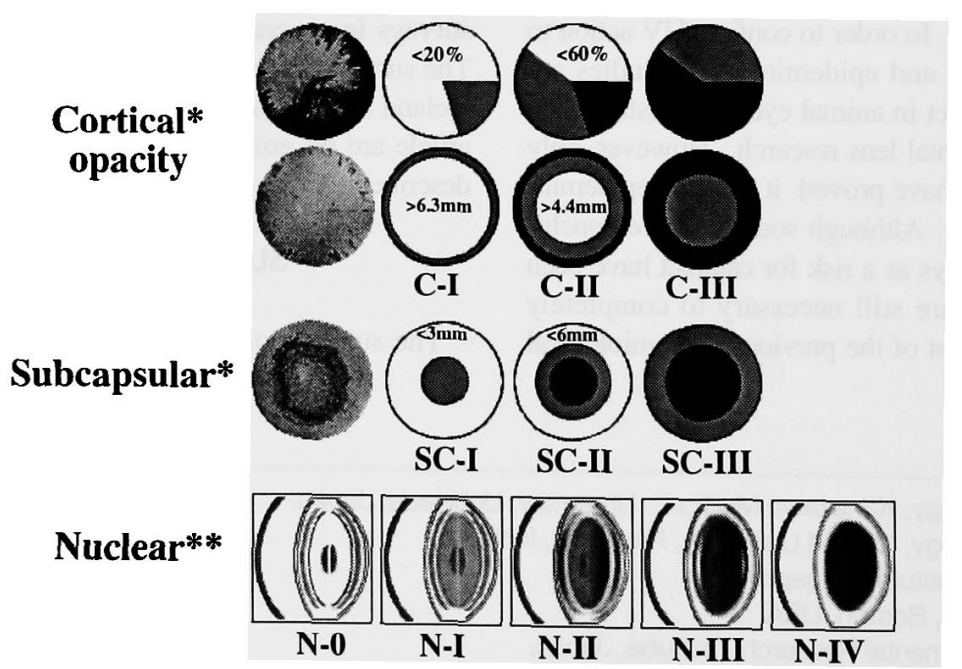

*Jpn-CCESG system, K. Sasaki, et.al. 1990 **KMU-NCC system, K. Sasaki, et.al. 1995

Figure 1. Classification and grading system ( JCCESG system and KMU system). 
throughout the study. Data was collected in three ways. : 1 . When data analysis dealt with the number of persons as well as type and grade of lens opacification, the worse eye was chosen. 2. If both eyes had the same grade of opacification but different opacification types, classification was done by the right eye. 3 . When comparing the prevalence of three main types of lens opacification, judgement was made from all of the opacification types existing in both lenses. If both eyes had the same type of opacification but different grades, classification was done by the higher grade. In the case - control studies regarding the time spent outdoors and appearance of cortical lens opacification, age and sex in the subjects were matched and cases and controls were divided into the subjects with cortical lens opacification and those with transparent lens.

The applied questionnaire was principally the same in all survey places and consisted of 26 items ${ }^{15}$. Among the questions relating to daily life, the individual's behavior outdoors was investigated as precisely as possible.

Statistical Methods. : For data analysis, the Student $\mathrm{t}$ test, $\chi^{2}$ test and Mantel Haenszel test were applied.

\section{RESULTS}

1. The prevalence of subjects with bilateral transparent lenses: The prevalence of subjects with bilateral lens transparency decreased with ageing in all groups, however, that in subjects in Noto and Reykjavik was higher than that in Amami and Singapore (Figure 2).

2 - i. The prevalence of lens opacification with grades I - III:
The increasing pattern of lens opacification was divided into two groups. One group contained subjects from Singapore and Amami and the other contained subjects from Noto and Reykjavik. Similarities were seen among the subjects in the same group (Figure 3a). The prevalence was significantly higher in the former than in the latter group. 2 - ii. The prevalence of lens opacification of grades II - III: \% of progressed lens opacification showed a characteristic increase in each subject group. Among the four subject groups, those in Singapore showed the highest \% and those in Reykjavik had the lowest (Figure 3b).

3. The prevalence of two main types of lens opacification over grade II: Prevalence of cortical opacification was significantly lower in the Icelandic subjects than in the Noto, Amami and Singaporean groups $(\mathrm{p}<0.01)$. There was no significant difference between the latter three groups. The prevalence of nuclear opacification was significantly higher in the Amami and Singaporean subjects than in the Noto and Icelandic subjects $(p<0.01)$. There was also a significant difference in the prevalence of nuclear opacification between the subjects in Amami and those in Singapore $(\mathrm{p}<0.01)$ (Figure 4).

4. The relationship between the history of time spent outdoors and cortical lens opacification in the Noto group was discussed in case (with lens opacification) and control (with transparent lens) studies. More than 5 hours spent outdoors daily in their $20 \mathrm{~s}-30 \mathrm{~s}, 40 \mathrm{~s}-50 \mathrm{~s}$ and at present showed a significant relative risk for the appearance of cataract in males (Table 2) .

\section{DISCUSSION}

In spite of general recognition that solar - UV rays have a harmful inversion effect on the ocular tissues, and on the lens

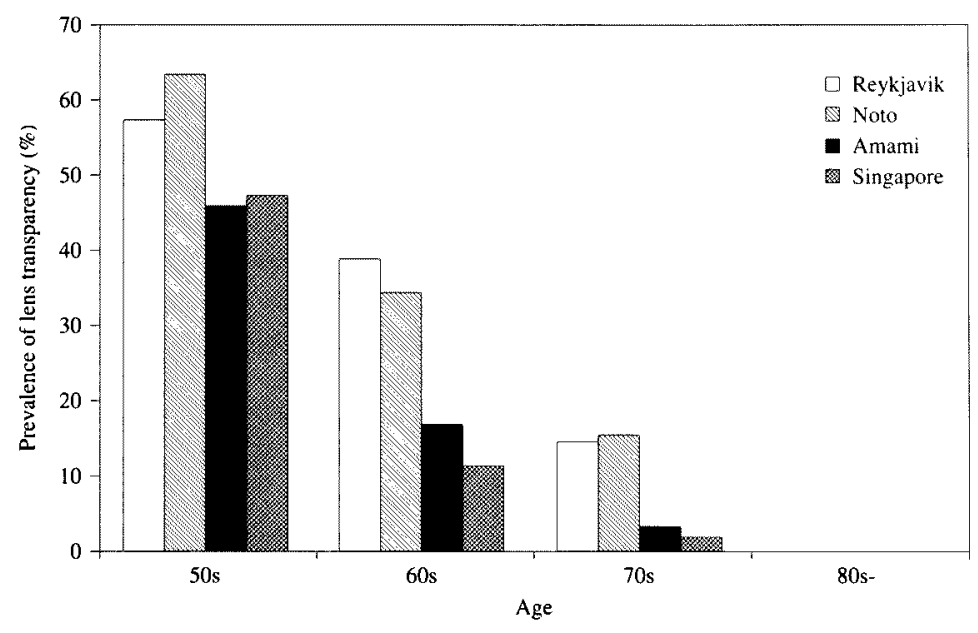

Figure 2. Prevalence of subjects with bilateral transparent lenses. 


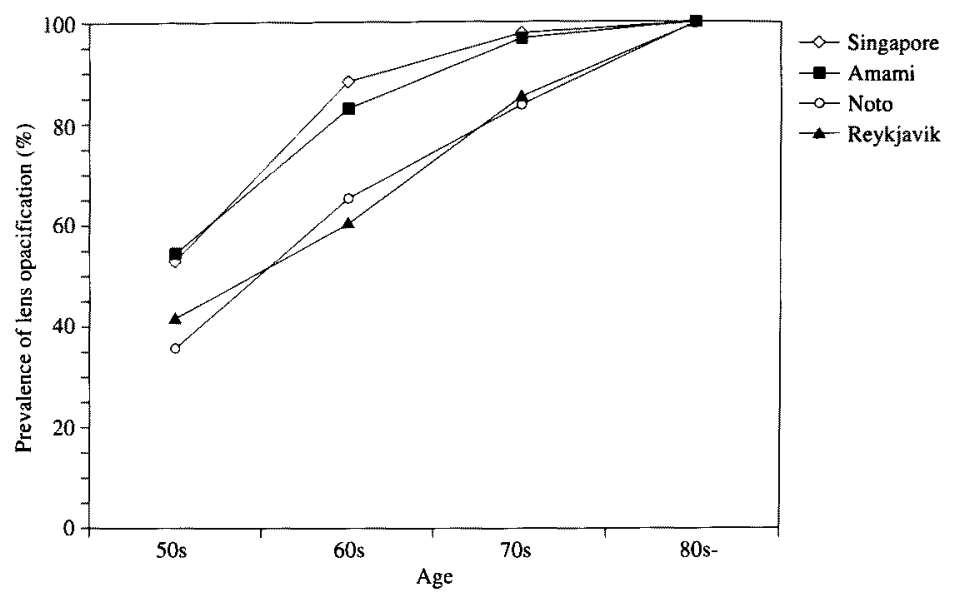

Figure 3a. Prevalence of lens opacification (Grade I - III).

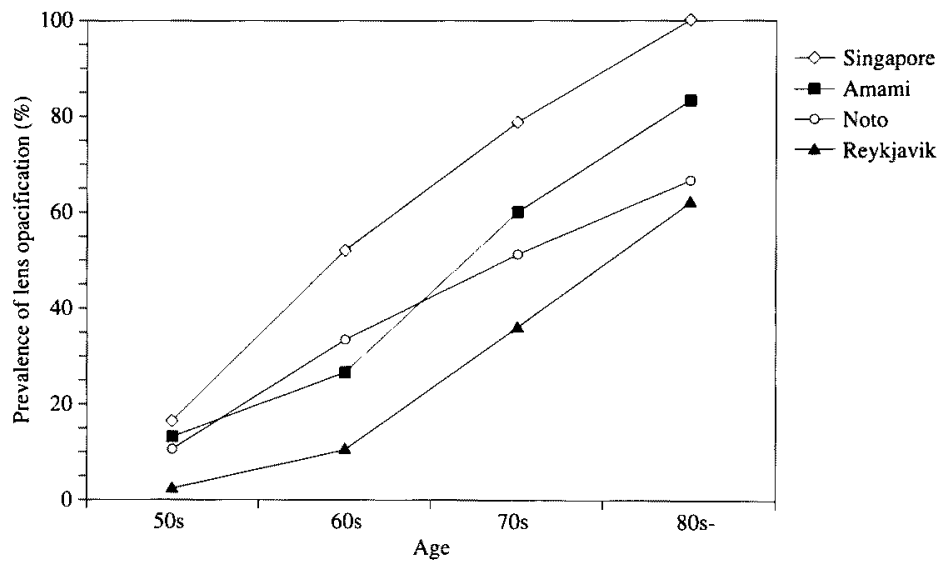

Figure 3b. Prevalence of lens opacification over Grade II.

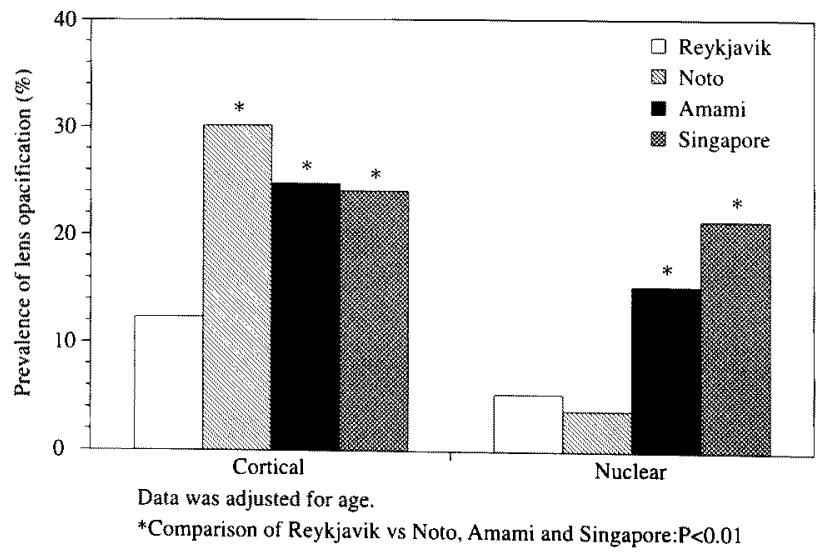

Figure 4. Prevalence of cortical and nuclear opacification over Grade II. 
Table 2. Odds ratio and $95 \%$ CI for cortical lens opacification (hours spent outside weekday).

\begin{tabular}{|c|c|c|}
\hline$<$ Noto $>$ & Male & Female \\
\hline$[20 s-30 s]$ & Relative Risk $(95 \% \mathrm{Cl})$ & Relative Risk (95\%Cl) \\
\hline-4 hours & 1.0 & 1.0 \\
\hline 5 - hours & $2.11(0.65-6.88)$ & $1.06(0.57-1.97)$ \\
\hline \multicolumn{3}{|l|}{$[40 s \sim 50 s]$} \\
\hline-4 hours & 1.0 & 1.0 \\
\hline 5 - hours & $3.88 *(1.11-13.53)$ & $0.93(0.51-1.71)$ \\
\hline \multicolumn{3}{|l|}{ [Present] } \\
\hline-4 hours & 1.0 & 1.0 \\
\hline 5 - hours & $2.20 *(1.03-4.71)$ & $0.64(0.38-1.05)$ \\
\hline
\end{tabular}

in particular ${ }^{16)}$, research to prove the UV-scenario has not yet reached its goal. Although cataract is recognized as a top ranking eye disease related with blindness ${ }^{1)}$, effective treatment is limited to surgery. At present there is still no definite proposal on how to prevent cataract. This is why proving the scenario is important. According to meteorological data, yearly UV exposure in Noto is over 3 times that of Iceland. Amami and Singapore are 5 times and 8 times that of Iceland. From this point alone, the results obtained from each study are worth considering as they relate to the scenario of solar UV induced cataract.

The increasing patterns of lens opacification were roughly divided into three groups: Amami and Singapore, Noto and Reykjavik. Regarding rather progressed cases, the highest \% of prevalence was seen in the subjects of Singapore and the lowest was seen in those of the Reykjavik group. It is epidemiologically significant that two Asian subject groups (Amami and Singapore) with similar climatical conditions of higher solar UV exposure showed a high prevalence of cataract.

The ambient UV level in Singapore, Amami and Noto was eight, five and three times that of Iceland. Furthermore, the time spent outside was longer in the Japanese subjects compared to the other two races (data not shown). From these points, the ocular exposure of UV irradiation might be significantly lower in Icelanders than in the other three groups. Although there was no difference in the prevalence of severe nuclear opacification in the Noto and Icelandic subjects, that of severe cortical opacification was significantly lower in the Icelanders compared to the other three groups. These findings might suggest the association between UV exposure and cortical cataract. The severe nuclear opacification was the highest in the Singaporeans followed by the Amami subjects. It was consistent with findings that the authors have reported on a high prevalence of nuclear opacification in Indonesian subjects ${ }^{17}$. While the data of the epidemiological studies disproved the association between nuclear opacification and solar UV exposure ${ }^{3,4,5,6)}$, the authors would like to consider that the nuclear findings observed in Singapore and Amami are a characteristic phenomenon in subjects who live in tropical or subtropical places.

As a risk factor search study, several items regarding individual solar UV exposure have been investigated and the authors' data supported the hypothesis that long periods of time spent outside are a risk for cortical opacification ${ }^{18)}$. Several epidemiological studies also pointed out the UV exposure as a risk of cortical cataract ${ }^{3,4,5,6,8)}$. Although the comparative study between Noto and the other subject groups is not yet completed, data from multi-survey places may give us useful information to establish preventative methods against UV induced ocular tissue damage.

\section{ACKNOWLEDGMENT}

The studies were supported by Global Environmental Research Fund.

\section{REFERENCES}

1. Thylefors B, Negel A-D, et al. : Global data on blindness An update. World Health Organization / PB 1994 ; 1 18.

2. Hockwin O, Wegener A: Syn- and Cocataractogenesis A System for testing subliminal lens toxicity - In: Druginduced Ocular Side Effects and Ocular Toxicology. Hockwin O (Ed.), Basel, Karger 1987, pp 241-249.

3. Taylor HR, West SK, Rosenthal FS, Munoz B, Newland $\mathrm{HS}$, Abbey $\mathrm{H}$, et al. Effect of ultraviolet radiation on cataract formation. N Engl J Med.1988 ; 319 : 1429 - 
1433.

4. The Italian - American Cataract Study group : Risk factors for age-related cortical, nuclear and posterior subcapsular cataracts. Am J Epidemiol 1991 ; 133 : 541 - 553.

5. Leske MC, Chylack LT, S-Y Wu, The Lens Opacities Case- Control Study Group : Arch Ophthalmol 1991 ; $109: 244$ - 251 .

6. Cruickshanks KJ, Klein BEK, Klein R : Ultraviolet light exposure and lens opacities: The Beaver Dam Eye Study. Am J Public Health $1992 ; 82$ : 1658 - 1662.

7. Sasaki K. Ono M, Aoki K, Katoh N, Morine M, Nakaizumi H, Fujisawa K, Kojima M, Sakamoto Y, Hatano $\mathrm{H}$ : Cataract epidemiology survey in the three different areas in Japan - Prevalence of cataracts and types of lens opacification. J Jpn Ophthalmolo Soc $1995 ; 99$ : 204-211.

8. West SK, Duncan DD, Munoz B, Rubin GS, Freid LP, Bandeen-Roche K, Scehin OD : Sunlight exposure and risk of lens opacities in a population-based study. The Salisbury Eye Evaluation Projects. JAMA $1998 ; 280$ : $714-718$.

9. Sasaki K : Epidemiology - Search for risk factors of cataract formation. Nova Acta Leopoldina NF 751997 ; $299: 25-36$.

10. Sasaki H, Asano K, Kojima M, Sakamoto Y, Kasuga T, Nagata M, Takahashi N, Sasaki K, Ono M, Katoh N : Epidemiological Survey of Ocular Diseases in $\mathbf{K}$ Island, Amami Islands : Prevalence of Cataract and Pterygium. J Jpn Ophthalmol Soc 1999 ; 103: 556-563.

11. Sasaki K, Sakamoto Y, Shibata T, Emori Y : Multi-pur- pose camera : A new anterior eye segment analysis system. Ophthalmic Res 1990 ; 22 (suppl) : 3-8.

12. Sasaki K : Cataract epidemiology performed with Scheimpflug documentation. Ophthalmic Res 1999 ; 31 : $75-85$.

13. Sasaki K, Shibata T, Obazawa H, Fujiwara T, Kogure F, Obara Y, Itoi M, Katoh K, Akiyama K, Okuyama S: Classification system for cataracts. Application by the Japanese Cooperative Cataract Epidemiology Study Group. Ophthalmic Res 1990 ; 22 (suppl) : 46-50.

14. Sasaki K, Sakamoto Y, Fujisawa K, Shibata $T$ : A new grading system for nuclear cataracts - An alternative to the Japanese Cooperative Cataract Epidemiology Study Group's grading. Dev Ophthalmol Basel, Karger 1997; $27: 42$ - 49.

15. Katoh N, Sasaki K, Obazawa H, Japanese Cooperative Cataract Epidemiology Study Group : Interview form applied to a cataract epidemiologic study. Dev Ophthalmol Basel, Karger $1991 ; 21: 108-114$.

16. WHO : The effect of solar UV radiation on the eye. Report of an information consultation, Geneva, 30.8. 3.9. , Publ WHO/PBL/ EHG/94, Geneva, 1993

17. Sasaki K, Zainuddin J, Fujisawa K, Kojima M, Sakamoto Y, Cataract epidemiology study in West Sumatra. Dev Ophthalmol Basel, Karger 1989; $17: 26$ - 32.

18. Shibata T, Sasaki K, Katoh N, Hatano T : Populationbased case-control study of cortical cataract in the Noto area, Japan. Dev Ophthalmol Basel, Karger 1994 ; 26 : 25-53. 